\title{
Comparative Study between the Practices of Exclusive Breastfeeding After Normal Delivery and Cesarean Delivery in Paropakar Maternity and Women's Hospital, Thapathali, Kathmandu Nepal
}

\author{
Rachana Aryal ${ }^{1}$, Kashyap Kumar Sharma ${ }^{2 *}$ \\ ${ }^{1}$ Department of Public Health, Nobel College, Sinamangal, Kathmandu, Nepal \\ ${ }^{2}$ Central Department of Statistics, Tribhuvan University, Nepal
}

\begin{abstract}
Breastfeeding is a special gift from a mother to her baby. If mother is successful in breast feeding during first few days of her baby's life, she is more likely to be successful during the rest of their breastfeeding time. The main aim of this study was to compare the practice of exclusive breastfeeding after normal delivery and cesarean delivery. This study also identified the initiation of breastfeeding within an hour, skin to skin contact between the mother and infant after the delivery and factors influencing for breastfeeding. A descriptive cross-sectional study design was used to collect the data from 300 samples. The total sample was divided into half which is 150 for each of the normal and cesarean deliveries. Inclusive criteria included of 20 to 30 years with the primiparous deliveries visiting the respective hospital for the different purpose were included. A self-administered questionnaire was verbally asked to each of the participants while collecting the data. The mode of delivery is significant with both initiation of breastfeeding within an hour $(\mathrm{p}<0.01$, chi square $=134.2)$ and skin to skin contact between mother and infant after delivery $(\mathrm{p}<0.01$, chi square $=185.9)$. From this study the perspective of the entire participants towards the breastfeeding is found to be on optimistic. ND is able to initiate the breastfeeding within an hour and can have skin to skin contact as soon as the delivery.
\end{abstract}

Keywords: Type of delivery, Exclusive Breastfeeding, Breastfeeding practices, Comparison

\section{Introduction}

Breast milk is best for the baby and the benefits of breastfeeding extend well beyond basic nutrition. In addition to containing all the vitamins and nutrients the baby needs in the first six months of life, breast milk is packed with disease fighting substances that protect your baby from illness. The child takes milk direct from the breast of the mother or expressed in the bottle. The first hour after childbirth is an excellent time to encourage the mother to breastfeed. The infant is typically in alter state and will suckle if put to the breast. For the first-time mothers are in need of reassurance, knowledge, motivation, and confidence building. To help mothers, you need information and skills to educate and counsel them. If mother is successful in breast feeding during first few days of her baby's life, she is more likely to be successful during the rest of their breastfeeding time [1]. 
In first postpartum week, the total amount of milk secreted in 24 hours is calculated to be 60 multiplied by the number of post-partum day and is expected in terms of milliliters. The milk yield on the $4^{\text {th }}$ day is about $60 * 4=240 \mathrm{ml}$ and by the end of second week the milk yield is $120-180 \mathrm{ml}$ per feeding. The more the baby sucks on the nipple, the more prolactin is released, resulting in increased milk secretion. The amount of prolactin secreted and hence the milk produced is related to the amount of sucking stimulus, which is the frequency, intensity and duration with which the baby is breast fed. Secretion is a continuous process unless suppressed by congestion or emotional disturbance. Feeds with bottles, incorrect positioning, and painful breast condition are hindering factors [1]. The baby friendly initiative is an international program of the World Health Organization (WHO) and United Nations Children's Fund (UNICEF) [2]. The initiative recognizes hospitals and birth centers have taken steps to provide an optional environment for the promotion, protection and support of breastfeeding. Since the inception of the Baby Friendly Hospital Initiative in 1991, more than 16,000 hospitals and birth centers in more than 125 countries have been assessed and received the prestigious 'Baby Friendly' award [2]. According to WHO, Exclusive Breastfeeding is defined as no other food or drink, not even water, except breast milk (including milk expressed or from a wet nurse) for 6 months of life, but allows the infant to receive ORS, drops and syrups (vitamins, minerals and medicines) [3]. Exclusive breastfeeding for the first 6 months of life is the recommended way of feeding infants, followed by continued breastfeeding with appropriate complementary foods for up to 2 years or beyond.

Normal delivery also known as vaginal delivery is the birth of babies through vagina which is considered to be the natural method. A spontaneous vaginal delivery (SVD) occurs when a pregnant female goes into labor without the use of drugs or techniques to induce labor and delivers the baby in normal manner without forceps, vacuum extraction, or a caesarean. An assisted or instrumental vaginal delivery occurs when a pregnant female goes into labor (with or without the use of drugs or techniques to induce labor) and requires the use of special instruments such as forceps or a vacuum extractor to deliver the baby vaginally. An induced vaginal delivery is a term for a delivery involving labor induction, where drugs or manual techniques are used to initiate process of labor.

Similarly, Cesarean section also known as C-section, is the use of surgery to deliver one or more babies. A caesarean section is often performed when a vaginal delivery would put the baby or mother at risk and some C-section are also performed upon request. The World Health Organization recommends that they should be done based on medical need and in many cases, they are life saving for the mother and baby. A C-section typically takes 45 minutes to an hour. It may be done with a spinal block such that the woman is awake or under general anesthesia. The average length of a hospital stay for a normal vaginal delivery is 3648 hours or with an episiotomy (a surgical cut to widen the vaginal canal) 48-60 hours, whereas a C-section is $72-108$ hours. The $\mathrm{C}$-section takes longer to heal from about six weeks than vaginal birth [4].

\section{Material and Methods}

Descriptive cross-sectional study design was used to collect the data from 300 sample size. A tablet or mobile has been used for data collection and storage using database software the Kobo toolbox platform. Consent was taken from participant by informing them purpose of the study. The total samples were divided into half which is 150 for each of the normal and cesarean deliveries. Inclusive criteria included of 20 to 30 years with the primiparous deliveries visiting the respective hospital for different purpose were included. Self-administered questionnaire was verbally asked to each of the participants while collecting the data. The sample size was calculated using the following equation.

$$
n=\frac{N Z^{2} P(1-P)}{(N-1) e^{2}+Z^{2} P(1-P)}
$$

Where,

$\mathrm{e}=$ Allowable error $(5 \%)$

$Z=$ Level of significance (1.96 at 5\% level of significance) 
Aryal et al. Adv. J Social Sci.; Vol. 1 Issue 1, pp: 40-52, November 2017

$\mathrm{N}=$ Total number of female provided from hospital in May and June 2017 is $670+702=1372$

$\mathrm{n}=$ Sample Female (300)

$\mathrm{P}=$ Probability $(0.5)$

The study only focused on mothers who delivered their babies from mid of April till the mid of June 2017 and who were exclusively breastfeeding their babies.

\section{Results}

From different study designs that could be used for the data collection, descriptive cross-sectional study design is chosen for this study. This type of research design does not require follow-up, therefore, less costly and less time intensive than other designs. For analysis of the data descriptive statistics including mean, frequencies and other statistical measures to analyze quantitative data collected. The qualitative data collected from interviews were based for the influencing factors and practice of breastfeeding. This study is carried out in Paropakar Maternity and Women's Hospital of Thapathali, Kathmandu, Nepal. The data for the study were collected from OPD, Vaccination department, Ward (ANC A- ANC B), Nutrition department, Library, Statistics department and emergency dept. The total sample size for the study is 300 which are selected from 1372 primi parous deliveries in mid-April to mid-May and mid-May to mid-June 2017. The data is collected equally with mothers of Normal Deliveries (ND) and Cesarean Deliveries (CS). For which the total sample size of ND and CS is 150 each respectively as shown

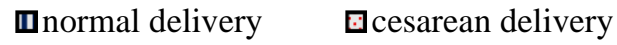

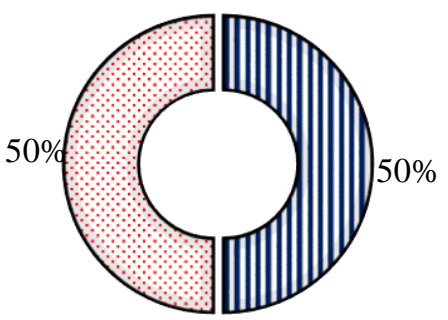
in Figure 1.

Figure 1: Method of delivery

Table 1: Ethnicity of the participant

The participants of the study were within the hospital from age 20 years to 30 years who had primi parous deliveries only. All the participants of ND had single child while only three out of 150 CS participants had twins. Table 1 illustrates that the study included a total of $32 \%$ of Brahmin, $30.3 \%$ of Others (Gurung, Limbu, Jantati, and Madhesi), $23.3 \%$ of Chhetri and $14.3 \%$ of Newar.

\begin{tabular}{|c|c|c|}
\hline Ethnicity & Frequency & Percent \\
\hline Brahmin & 96 & 32 \\
\hline Chhetri & 70 & 23.3 \\
\hline Newar & 43 & 14.3 \\
\hline Others & 91 & 30.3 \\
\hline Total & $\mathbf{3 0 0}$ & $\mathbf{1 0 0}$ \\
\hline
\end{tabular}

Table 2: Religion of the participants

The majority of the participants were Hindu with $76 \%$ followed by Buddhist with $12 \%$, Christian $7.3 \%$ and Muslim $4.7 \%$ as shown in Table 2.

\subsection{Comparing Normal Delivery (Nd) and Cesarean Delivery (Cs)}

\subsubsection{Education Status}

\begin{tabular}{|c|c|c|}
\hline Religion & Frequency & Percent \\
\hline Hindu & 228 & 76 \\
\hline Buddhist & 36 & 12 \\
\hline Christian & 22 & 7.3 \\
\hline Muslim & 14 & 4.7 \\
\hline Total & $\mathbf{3 0 0}$ & $\mathbf{1 0 0}$ \\
\hline
\end{tabular}

The descriptive information of education status of the participants is displayed in the Table 3. Table 3 shows that out of 150 participants of normal delivery $80.7 \%$ could read and write and $19.3 \%$ couldn't read and write. Similarly, the 150 participants of cesarean delivery 91\% could read and write and $8.7 \%$ couldn't read and write. 


\subsubsection{Education level}

The descriptive information of education level of the participants is displayed in the Table 4.
Table 3: Education status of the participants

\begin{tabular}{|c|c|c|c|}
\hline Methods of delivery & Education status & Frequency & Percent \\
\hline \multirow{4}{*}{ Normal delivery } & Can read and write & 121 & 80.7 \\
\cline { 2 - 4 } & Cannot read and write & 29 & 19.3 \\
\cline { 2 - 4 } & Total & $\mathbf{1 5 0}$ & $\mathbf{1 0 0}$ \\
\hline \multirow{4}{*}{ Cesarean delivery } & Can read and write & 137 & 91.3 \\
\cline { 2 - 4 } & Cannot read and write & 13 & 8.7 \\
\cline { 2 - 4 } & Total & $\mathbf{1 5 0}$ & $\mathbf{1 0 0}$ \\
\hline
\end{tabular}

Table 4: Education level

Table 4 shows that out of the total participant who could read and write, $33.3 \%$ of primary level, $24 \%$ have studied above SLC and $23.3 \%$ up to SLC among ND. In the same way, among CS $36 \%$ have studied above SLC, $34 \%$ of primary level and $21.3 \%$ up to SLC.

\subsubsection{Employment status}

\begin{tabular}{|c|c|c|c|}
\hline Methods of delivery & Education level & Frequency & Percent \\
\hline \multirow{4}{*}{ Normal delivery } & Primary & 50 & 33.3 \\
\cline { 2 - 4 } & SLC & 35 & 23.3 \\
\cline { 2 - 4 } & Above SLC & 36 & 24 \\
\cline { 2 - 4 } & Total & $\mathbf{1 2 1}$ & $\mathbf{8 0 . 7}$ \\
\hline \multirow{4}{*}{ Cesarean delivery } & Primary & 51 & 34 \\
\cline { 2 - 4 } & SLC & 32 & 21.3 \\
\cline { 2 - 4 } & Above SLC & 54 & 36 \\
\cline { 2 - 4 } & Total & $\mathbf{1 3 7}$ & $\mathbf{9 1 . 3}$ \\
\hline
\end{tabular}

Table 5: Employment status

The descriptive information about employment status of the participants is displayed in Table 5. Table 5 illustrates the employment status with maximum participants of both normal and cesarean deliveries were housewives with $64.7 \%$ and $57.3 \%$ and few were students with $6 \%$ and $2 \%$ respectively. $17.3 \%$ were selfemployed and $12 \%$ were into

\begin{tabular}{|c|c|c|c|}
\hline Methods of delivery & Employment status & Frequency & Percent \\
\cline { 2 - 4 } & Self employed & 26 & 17.3 \\
\cline { 2 - 4 } & Services & 18 & 12 \\
\cline { 2 - 4 } & Student & 9 & 6 \\
\cline { 2 - 4 } Normal delivery & House wife & 97 & 64.7 \\
\cline { 2 - 4 } & Total & $\mathbf{1 5 0}$ & $\mathbf{1 0 0}$ \\
\hline \multirow{7}{*}{ Cesarean delivery } & Self employed & 20 & 13.3 \\
\cline { 2 - 4 } & Services & 41 & 27.3 \\
\cline { 2 - 4 } & Student & 3 & 2 \\
\cline { 2 - 4 } & House wife & 86 & 57.3 \\
\cline { 2 - 4 } & Total & $\mathbf{1 5 0}$ & $\mathbf{1 0 0}$ \\
\hline
\end{tabular}
service in ND where as $27.3 \%$ were into service and $13.3 \%$ were self- employed in CS.

\subsubsection{Workplace Providing Private Place to Breastfeed or Express Milk}

Table 6: Workplace providing private place to breastfeed or express milk

The descriptive information of work area providing private place to breastfeed or express the milk for the child is displayed in Table 6. This Table 6 shows both the ND and CS participants accepted having a private place to breastfeed or express the breast milk for the

\begin{tabular}{|c|c|c|c|}
\hline $\begin{array}{c}\text { Methods of } \\
\text { delivery }\end{array}$ & $\begin{array}{c}\text { Private place to } \\
\text { breastfeed or express } \\
\text { milk }\end{array}$ & Frequency & Percent \\
\hline \multirow{4}{*}{ Normal delivery } & Yes & 128 & 85.3 \\
\cline { 2 - 4 } & No & 22 & 14.7 \\
\cline { 2 - 4 } & Total & $\mathbf{1 5 0}$ & $\mathbf{1 0 0}$ \\
\cline { 2 - 4 } $\begin{array}{c}\text { Cesarean } \\
\text { delivery }\end{array}$ & Yes & 112 & 74.7 \\
\cline { 2 - 4 } & No & 38 & 25.3 \\
\hline
\end{tabular}
baby with $85.3 \%$ and $74.7 \%$ respectively. $14.7 \%$ of ND and $25.3 \%$ of CS have denied for not having a private place to breastfeed of express the milk for the baby. 
Aryal et al. Adv. J Social Sci.; Vol. 1 Issue 1, pp: 40-52, November 2017

\subsubsection{The Stay in the Hospital}

The descriptive information of participants staying in the hospital is displayed in Figure 2.

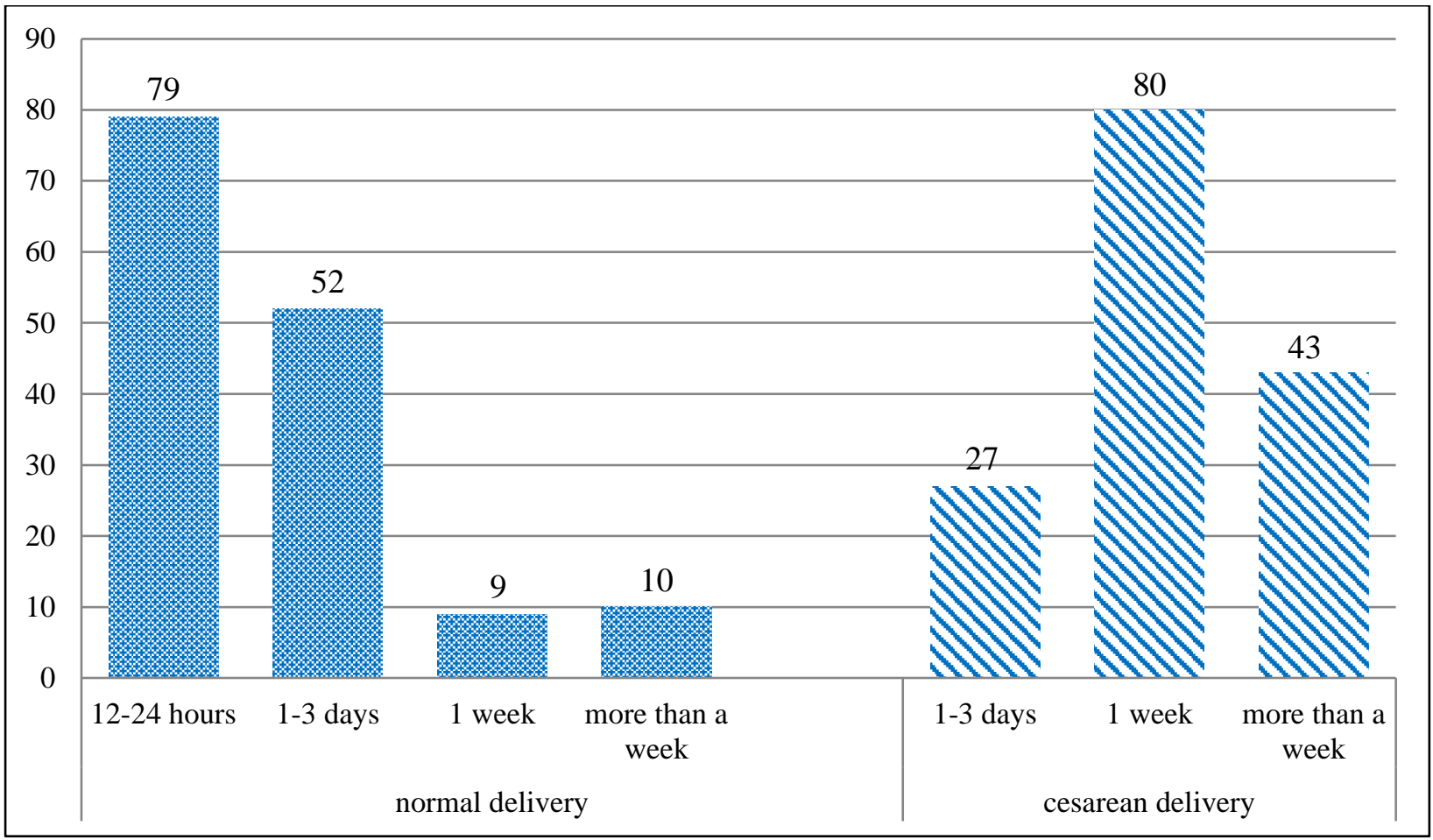

Figure 2: The stay in the hospital

Figure 2 illustrates that the maximum participants of ND got discharge within 12-24 hours followed by 13 days. Only few got discharge in a week and more than a week respectively. Similarly, the maximum participants of CS got discharge in a week followed by more than a week and 1-3 days accordingly. Nobody of CS got discharged within 12-24 hours.

\subsubsection{Initiation of Breastfeeding in the First Hour of Delivery}

The descriptive information of initiation of breastfeeding in the first hour of delivery is displayed in Figure 3.

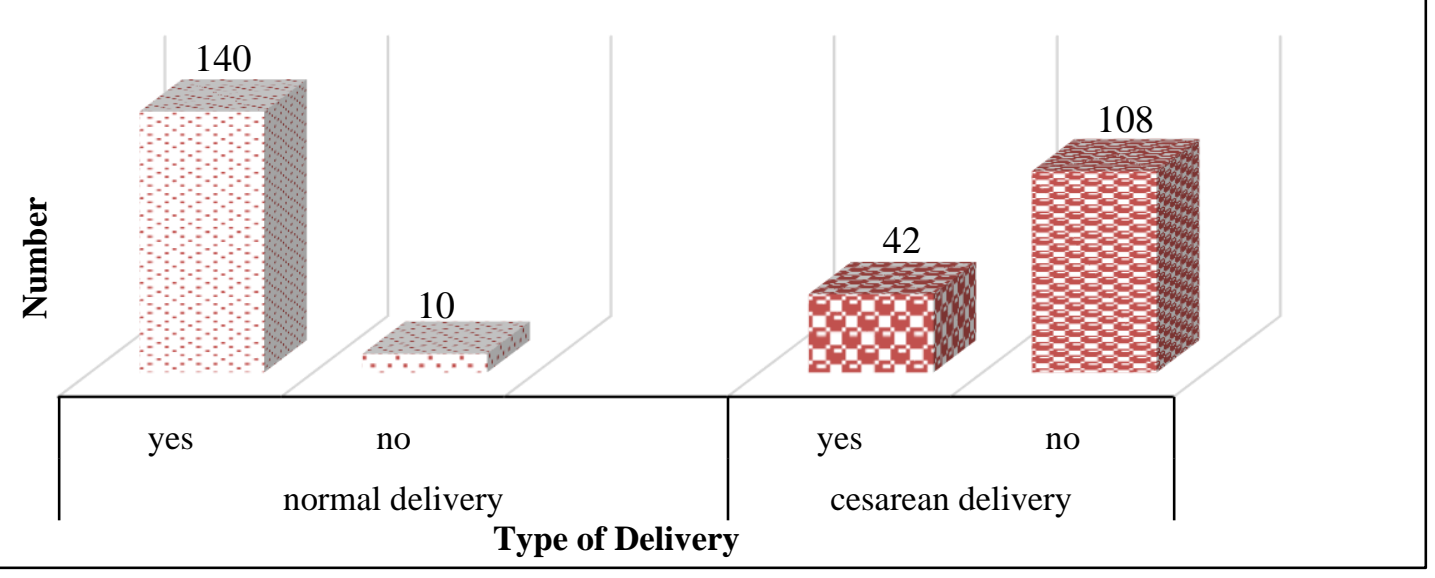

Figure 3: Initiation of breastfeeding in the first hour of delivery

Out of 150 each participants of both deliveries, total 140 ND participants initiated breastfeeding within an hour of delivery but, only 108 CS participants did not initiated breastfeeding within an hour of delivery. 
Comparative Study between the Practices of Exclusive Breastfeeding After Normal Delivery and Cesarean Delivery ....

\subsubsection{Reasons for Not Initiating Breastfeeding Within an Hour}

Table7: Reasons for not initiating breastfeeding within an hour

The descriptive information of reasons for not initiating breastfeeding within an hour is displayed in Table 7. As Table 7 shows the CS participants were higher in not initiating the breastfeeding within an hour the maximum reason was because mother was sick with 34\% followed by baby taken away from mother

\begin{tabular}{|c|c|c|c|}
\hline $\begin{array}{c}\text { Methods of } \\
\text { delivery }\end{array}$ & $\begin{array}{c}\text { Reasons for not initiating } \\
\text { breastfeeding within an hour }\end{array}$ & $\begin{array}{c}\text { Frequenc } \\
\mathbf{y}\end{array}$ & $\begin{array}{c}\text { Percen } \\
\mathbf{t}\end{array}$ \\
\hline \multirow{4}{*}{ Normal delivery } & No milk & 1 & 0.66 \\
\cline { 2 - 4 } & Mother was sick & 5 & 3.33 \\
\cline { 2 - 4 } & $\begin{array}{c}\text { Baby was taken away from } \\
\text { mothers }\end{array}$ & 4 & 2.66 \\
\cline { 2 - 4 } & Total & $\mathbf{1 0}$ & $\mathbf{6 . 6 6}$ \\
\cline { 2 - 4 } & No milk & 25 & 16.66 \\
\cline { 2 - 4 } Cesarean delivery & Mother was sick & 51 & 34 \\
\cline { 2 - 4 } & $\begin{array}{c}\text { Baby wasen away from } \\
\text { mothers }\end{array}$ & 32 & 21.33 \\
\cline { 2 - 4 } & Total & $\mathbf{1 0 8}$ & $\mathbf{7 2}$ \\
\hline
\end{tabular}
with $21.3 \%$ and no milk with $16.7 \%$. Only $6.7 \%$ ND participants did not initiate breastfeeding within an hour, the reason was because mother was sick $(3.3 \%)$ and baby was taken away from mothers $(2.7 \%)$.

\subsubsection{Breastfeeding the Baby for the First Time by the Mother Herself}

Table 8: Breastfeeding the baby for the first time by the mother herself

The descriptive information of breastfeeding the baby for the first time by the mother herself is displayed in Table 8. From the Table $8,81.3 \%$ of ND mothers tried to breastfeed their babies within 1-3 hour after birth for the first time on their own, whereas $36 \%$ of CS mothers tried to breast feed their babies within 411 hours after birth

\begin{tabular}{|c|c|c|c|}
\hline $\begin{array}{c}\text { Methods of } \\
\text { delivery }\end{array}$ & $\begin{array}{c}\text { Breastfeeding by the mother } \\
\text { herself for the first time }\end{array}$ & Frequency & $\mathbf{\%}$ \\
\hline \multirow{4}{*}{ Normal delivery } & $1-3$ hours after birth & 122 & 81.33 \\
\cline { 2 - 4 } & $4-11$ hours after birth & 18 & 12 \\
\cline { 2 - 4 } & $12-23$ hours after birth & 6 & 4 \\
\cline { 2 - 4 } & 24 hours or more after birth & 4 & 2.66 \\
\hline \multirow{4}{*}{$\begin{array}{c}\text { Total } \\
\text { Cesarean } \\
\text { delivery }\end{array}$} & $1-3$ hours after birth & $\mathbf{1 5 0}$ & $\mathbf{1 0 0}$ \\
\cline { 2 - 4 } & $4-11$ hours after birth & 54 & 21.33 \\
\cline { 2 - 4 } & $12-23$ hours after birth & 25 & 36 \\
\cline { 2 - 4 } & 24 hours or more after birth & 39 & 26 \\
\hline \multirow{4}{*}{ Total } & $\mathbf{1 5 0}$ & $\mathbf{1 0 0}$ \\
\hline
\end{tabular}
followed by $26 \%, 21.3 \%$ and $16.7 \%$ with 24 hours or more after birth, $1-3$ hours after birth and $12-23$ hours after birth.

\subsubsection{Skin to Skin Contact with the Baby After Birth}

The descriptive information about skin to skin contact of mother and baby after birth is displayed in Figure 4.

In normal delivery $96.7 \%$ of mothers had skin to skin contact with the baby after birth whereas, in cesarean delivery $81.3 \%$ did not had a chance for skin to skin contact with the baby after birth.

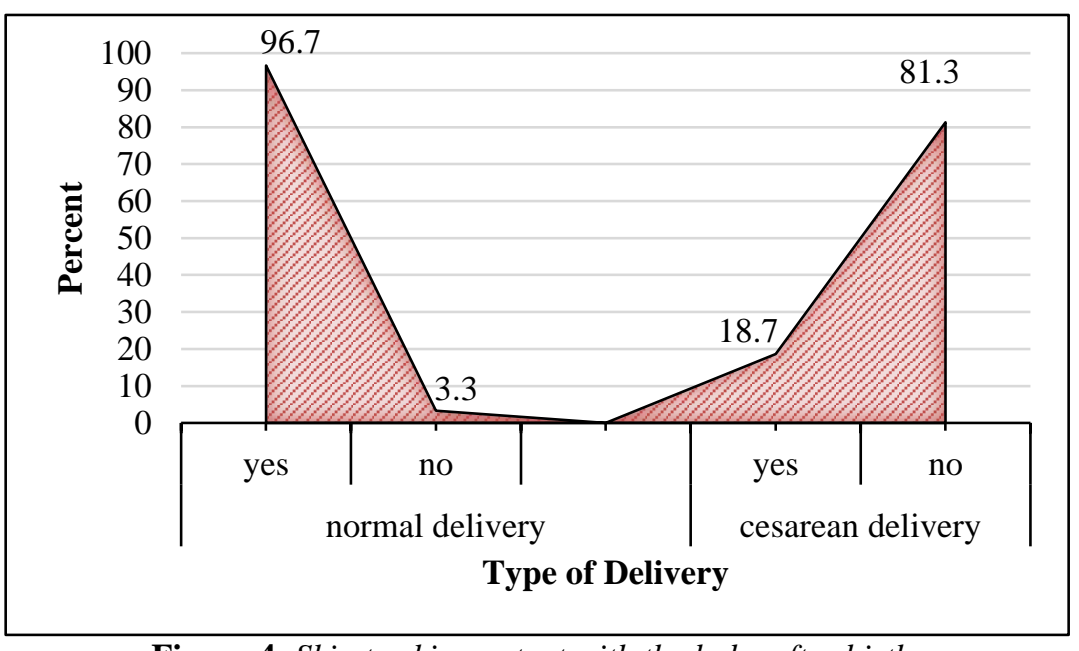

Figure 4: Skin to skin contact with the baby after birth 
Aryal et al. Adv. J Social Sci.; Vol. 1 Issue 1, pp: 40-52, November 2017

\subsubsection{Received Hospital Staff's Help for Feeding their Baby}

Table 9: Received hospital staff's help for feeding their baby

The descriptive information about the help received from hospital staff for feeding the baby is displayed in Table 9. From Table 9, 88.7\% and $83.3 \%$ of participants of ND and CS received the help for feeding the baby from hospital staff respectively.

\begin{tabular}{|c|c|c|c|}
\hline Methods of delivery & $\begin{array}{c}\text { Help from } \\
\text { hospital staff for } \\
\text { feeding the baby }\end{array}$ & Frequency & Percent \\
\hline \multirow{4}{*}{ Normal delivery } & Yes & 133 & 88.66 \\
\cline { 2 - 4 } & No & 17 & 11.33 \\
\hline \multirow{3}{*}{ Cesarean delivery } & Total & $\mathbf{1 5 0}$ & $\mathbf{1 0 0}$ \\
\cline { 2 - 4 } & Yes & 125 & 83.33 \\
\cline { 2 - 4 } & No & 25 & 16.66 \\
\hline
\end{tabular}

\subsubsection{Help by the Staff Regarding Feeding}

Table 10: The help by hospital staff regarding feeding.

The descriptive information about how useful the help received from hospital staff was, for feeding the baby is displayed in Table 10. As shown in Table $10,62 \%$ and $54 \%$ of the ND and CS participants found the help of feeding from the hospital staff found very useful.

\begin{tabular}{|c|c|c|c|}
\hline $\begin{array}{c}\text { Methods of } \\
\text { delivery }\end{array}$ & $\begin{array}{c}\text { Usefulness of hospital } \\
\text { staffs' help for feeding }\end{array}$ & $\begin{array}{c}\text { Freque } \\
\text { ncy }\end{array}$ & $\begin{array}{c}\text { Perc } \\
\text { ent }\end{array}$ \\
\hline \multirow{3}{*}{$\begin{array}{c}\text { Normal } \\
\text { delivery }\end{array}$} & Very useful & 93 & 62 \\
\cline { 2 - 4 } & Not useful & 40 & 26.66 \\
\hline \multirow{3}{*}{$\begin{array}{c}\text { Cesarean } \\
\text { delivery }\end{array}$} & Total & $\mathbf{1 3 3}$ & $\mathbf{8 8 . 6 6}$ \\
\cline { 2 - 4 } & Very useful & 82 & 54.66 \\
\cline { 2 - 4 } & Not useful & 43 & 28.66 \\
\hline
\end{tabular}

\subsubsection{Baby Fed Anything other than Breast Milk after Starting Breastfeeding}

Table 11: Baby fed anything other than breast milk after starting breastfeeding

The descriptive information if baby fed anything other than breast milk and fed items to the baby is displayed in Table 11 and Figure 5 accordingly. Table 11 illustrates that $84.7 \%$ of ND participants did not feed and $56 \%$ of CS participants fed other than breast milk after they had started breastfeeding.

In the same way, from Figure 5 below

\begin{tabular}{|c|c|c|c|}
\hline $\begin{array}{c}\text { Methods of } \\
\text { delivery }\end{array}$ & $\begin{array}{c}\text { Fed anything other } \\
\text { than breast milk to } \\
\text { baby }\end{array}$ & $\begin{array}{c}\text { Frequen } \\
\text { cy }\end{array}$ & $\begin{array}{c}\text { Perce } \\
\text { nt }\end{array}$ \\
\hline \multirow{4}{*}{$\begin{array}{c}\text { Normal } \\
\text { delivery }\end{array}$} & Yes & 23 & 15.33 \\
\cline { 2 - 4 } & No & 127 & 84.66 \\
\hline \multirow{3}{*}{$\begin{array}{c}\text { Cesarean } \\
\text { delivery }\end{array}$} & Yes & $\mathbf{1 5 0}$ & $\mathbf{1 0 0}$ \\
\cline { 2 - 4 } & No & 64 & 56 \\
\cline { 2 - 4 } & Total & $\mathbf{1 5 0}$ & $\mathbf{1 0 0}$ \\
\hline
\end{tabular}
shows that Formula and glucose was fed to the babies other than breast milk of ND and of CS, with highest preferences to formula feeding.

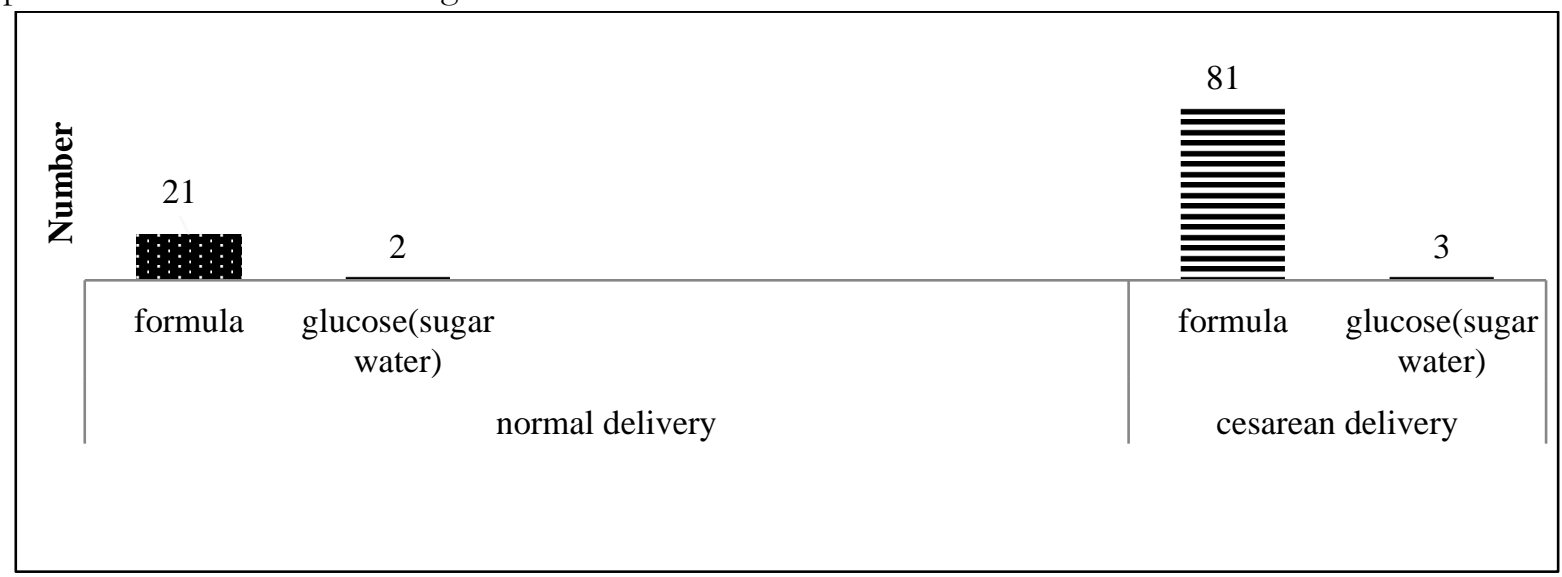

Figure 5: Fed items to the baby 
Comparative Study between the Practices of Exclusive Breastfeeding After Normal Delivery and Cesarean Delivery ....

\subsubsection{Developed Breast Problems}

Table 12: Developed cracked nipples/breast abscess/ any breast problem

The descriptive information of developing cracked nipples/breast abscess/ any other breast problems and if they stopped breastfeeding after the problems or not are displayed in Table 12 and Table 13 respectively.

\begin{tabular}{|c|c|c|c|}
\hline Methods of delivery & Developed any breast problem & Frequency & Percent \\
\hline \multirow{4}{*}{ Normal delivery } & Yes & 109 & 72.66 \\
\cline { 2 - 4 } & No & 41 & 27.33 \\
\hline \multirow{3}{*}{ Cesarean delivery } & Total & $\mathbf{1 5 0}$ & $\mathbf{1 0 0}$ \\
\cline { 2 - 4 } & Yes & 105 & 70 \\
\cline { 2 - 4 } & No & 45 & 30 \\
\hline \multicolumn{2}{|c|}{ Total } & $\mathbf{1 5 0}$ & $\mathbf{1 0 0}$ \\
\hline
\end{tabular}

Table 13: Stop breastfeeding during breast problems

Table 12 shows the participants of both ND and CS developed cracked nipples/ breast abscess/ any breast problems with $72.7 \%$ and $30 \%$ respectively. Similarly, the Table 13 shows that, $88 \%$ and $80 \%$ of ND and CS mothers did not stop breastfeeding even after the breast problems. But $12 \%$

\begin{tabular}{|c|c|c|c|}
\hline $\begin{array}{c}\text { Methods of } \\
\text { delivery }\end{array}$ & $\begin{array}{c}\text { Stop breastfeeding } \\
\text { during breast problems }\end{array}$ & Frequency & Percent \\
\hline \multirow{3}{*}{$\begin{array}{c}\text { Normal } \\
\text { delivery }\end{array}$} & Yes & 18 & 12 \\
\cline { 2 - 4 } & No & 132 & 88 \\
\hline \multirow{3}{*}{$\begin{array}{c}\text { Cesarean } \\
\text { delivery }\end{array}$} & Total & $\mathbf{1 5 0}$ & $\mathbf{1 0 0}$ \\
\cline { 2 - 4 } & Yes & 30 & 20 \\
\cline { 2 - 4 } & No & 120 & 80 \\
\hline
\end{tabular}
and $20 \%$ of them stopped breast feeding due to various breast problems.

\subsubsection{Express the Breast Milk for the Baby to Taken when the Mother is Away}

Table 14: Express the breast milk for the baby to take when the mother is away.

The descriptive information about expressing the breast milk for the baby to take when the mother is away is displayed in Table 14. Table 14 shows the majority of participants of both normal delivery and cesarean delivery did not practice the method of expressing the breast milk in the

\begin{tabular}{|c|c|c|c|}
\hline $\begin{array}{c}\text { Methods of } \\
\text { delivery }\end{array}$ & $\begin{array}{c}\text { Express the breast } \\
\text { milk for the baby }\end{array}$ & Frequency & Percent \\
\hline \multirow{3}{*}{$\begin{array}{c}\text { Normal } \\
\text { delivery }\end{array}$} & Yes & 45 & 30 \\
\cline { 2 - 4 } & No & 105 & 70 \\
\hline \multirow{3}{*}{$\begin{array}{c}\text { Cesarean } \\
\text { delivery }\end{array}$} & Total & $\mathbf{1 5 0}$ & $\mathbf{1 0 0}$ \\
\cline { 2 - 4 } & Yes & 43 & 28.66 \\
\cline { 2 - 4 } & No & 107 & 71.33 \\
\hline
\end{tabular}
bottle if the baby is unable to suck the milk directly from mother's breast. Only around 30 percentages of both the deliveries practiced the method expressing the breast milk.

\subsubsection{Measurement of the Breast Milk Before Feeding the Baby}

Table 15: Measurement of the breast milk before feeding the baby

The descriptive information about measuring the breast milk before feeding the baby is displayed in Table 15. This Table shows only $24 \%$ and $37.3 \%$ of ND and CS participants measure the breast milk before feeding their babies. Rests of other

\begin{tabular}{|c|c|c|c|}
\hline $\begin{array}{c}\text { Methods of } \\
\text { delivery }\end{array}$ & $\begin{array}{c}\text { Measurement of breast } \\
\text { milk before feeding the } \\
\text { baby }\end{array}$ & Frequency & Percent \\
\hline \multirow{4}{*}{ Normal delivery } & Yes & 36 & 24 \\
\cline { 2 - 4 } & No & 114 & 76 \\
\cline { 2 - 4 } & Total & $\mathbf{1 5 0}$ & $\mathbf{1 0 0}$ \\
\cline { 2 - 4 } $\begin{array}{c}\text { Cesarean } \\
\text { delivery }\end{array}$ & Yes & 56 & 37.33 \\
\cline { 2 - 4 } & No & 94 & 62.66 \\
\hline
\end{tabular}
participants do not measure the breast milk. 
Aryal et al. Adv. J Social Sci.; Vol. 1 Issue 1, pp: 40-52, November 2017

\subsubsection{Milk on Average that was Fed to the Baby}

Table 16: Milk on average that was fed to the baby

The descriptive information about an average $\mathrm{ml}$ of milk fed to the baby is displayed in Table 16. Table 16 illustrates that the maximum participants of both the deliveries did not know about the average milk fed to the baby. $16 \%, 9.3 \%$ and $1.3 \%$ said $45 \mathrm{ml}, 30 \mathrm{ml}$, and $15 \mathrm{ml}$ respectively of ND. $20.6 \%$, $18 \%$ and $4 \%$ said $45 \mathrm{ml}, 30 \mathrm{ml}$ and $15 \mathrm{ml}$ respectively of CS.

\begin{tabular}{|c|c|c|c|}
\hline Methods of delivery & Fed milk on average & Frequency & Percent \\
\hline \multirow{4}{*}{ Normal delivery } & $15 \mathrm{ml}$ & 2 & 1.33 \\
\cline { 2 - 4 } & $30 \mathrm{ml}$ & 14 & 9.33 \\
\cline { 2 - 4 } & $45 \mathrm{ml}$ & 24 & 16 \\
\cline { 2 - 4 } & don't know & 110 & 73.33 \\
\cline { 2 - 4 } & Total & $\mathbf{1 5 0}$ & $\mathbf{1 0 0}$ \\
\cline { 2 - 4 } & $15 \mathrm{ml}$ & 6 & 4 \\
\cline { 2 - 4 } & $30 \mathrm{ml}$ & 27 & 18 \\
\cline { 2 - 4 } & $45 \mathrm{ml}$ & 31 & 20.66 \\
\cline { 2 - 4 } Cesarean delivery & don't know & 86 & 57.33 \\
\cline { 2 - 4 } & Total & $\mathbf{1 5 0}$ & $\mathbf{1 0 0}$ \\
\hline
\end{tabular}

\subsection{Opinion of Participants Towards Breastfeeding}

The descriptive information about the opinion of participants of normal delivery and cesarean delivery towards breastfeeding is displayed in Table 17 and Table 18 respectively.

Table 17: Opinion of ND participants

\begin{tabular}{|c|c|c|c|}
\hline Opinions & $\begin{array}{c}\text { Agree } \\
\mathbf{( \% )}\end{array}$ & $\begin{array}{c}\text { Neutral } \\
(\boldsymbol{\%})\end{array}$ & $\begin{array}{c}\text { Disagree } \\
\mathbf{( \% )}\end{array}$ \\
\hline $\begin{array}{c}\text { Benefits of breastfeeding are limited for a specific } \\
\text { period. }\end{array}$ & 12.66 & 25.33 & 62 \\
\hline $\begin{array}{c}\text { Breast feeding is more convenient than formula } \\
\text { feeding. }\end{array}$ & 84.66 & 13.33 & 2 \\
\hline $\begin{array}{c}\text { Breastfed babies are healthier than formula fed } \\
\text { infants. }\end{array}$ & 83.33 & 14.6 & 2 \\
\hline $\begin{array}{c}\text { Formula fed babies are more likely to gain weight } \\
\text { more quickly than breastfed infants. }\end{array}$ & 40 & 32.66 & 27.33 \\
\hline Breast milk is cheaper than formula. & 96.66 & 2.66 & 0.66 \\
\hline Breast milk is ideal food for babies. & 92.66 & 6 & 1.33 \\
\hline $\begin{array}{c}\text { Breast feeding can enhance intimacy between } \\
\text { mother and infant. }\end{array}$ & 93.33 & 6 & 0.66 \\
\hline $\begin{array}{c}\text { If mother intend to resume work, formula feeding } \\
\text { is a better choice. }\end{array}$ & 65.33 & 24.66 & 10 \\
\hline $\begin{array}{c}\text { Women should not breastfeed in public places } \\
\text { (such as restaurants). }\end{array}$ & 7.33 & 36.66 & 56 \\
\hline $\begin{array}{c}\text { It is better to avoid breastfeeding to prevent } \\
\text { physical changes in mother's body. }\end{array}$ & 2 & 20.66 & 77.33 \\
\hline
\end{tabular}

The above Table 17 shows the majority of ND participants find breast milk cheaper and as an ideal food for the baby with around 96 and $92 \%$ respectively. They also prefer breastfeeding to be much more convenient, healthier and is able to improve the bond of mother and a child. Very less participants agree with the opinion that breastfeeding is limited for specific duration and has negative impact physically.

Similarly, Table 18 below majority of CS participants also found breast milk more convenient, healthier, cheaper and ideal food for the baby. While higher percent of participants have also agreed, formula feeding is better choice if mother intends to resume work. 
Comparative Study between the Practices of Exclusive Breastfeeding After Normal Delivery and Cesarean Delivery ....

Table 18: Opinion of CS participants

\begin{tabular}{|c|c|c|c|}
\hline Opinions & Agree (\%) & Neutral $(\%)$ & Disagree (\%) \\
\hline Benefits of breastfeeding are limited for a specific period. & 22.66 & 16.66 & 60.66 \\
\hline Breast feeding is more convenient than formula feeding. & 90 & 4 & 6 \\
\hline Breastfed babies are healthier than formula fed infants. & 88.66 & 8.66 & 2.66 \\
\hline $\begin{array}{l}\text { Formula fed babies are more likely to gain weight more } \\
\text { quickly than breastfed infants. }\end{array}$ & 50.66 & 21.33 & 28 \\
\hline Breast milk is cheaper than formula. & 94 & 2.66 & 3.33 \\
\hline Breast milk is ideal food for babies. & 80 & 4 & 16 \\
\hline $\begin{array}{l}\text { Breast feeding can enhance intimacy between mother and } \\
\text { infant. }\end{array}$ & 95.33 & 4 & 0.66 \\
\hline $\begin{array}{l}\text { If mother intend to resume work, formula feeding is a better } \\
\text { choice. }\end{array}$ & 76.66 & 16 & 7.33 \\
\hline $\begin{array}{l}\text { Women should not breastfeed in public places (such as } \\
\text { restaurants). }\end{array}$ & 10.66 & 25.33 & 64 \\
\hline $\begin{array}{l}\text { It is better to avoid breastfeeding to prevent physical changes } \\
\text { in mother's body. }\end{array}$ & 1.33 & 8 & 90.66 \\
\hline
\end{tabular}

\subsection{Relationship between the Modes of Delivery and Initiation of Breastfeeding within an Hour}

The descriptive information about the association between the mode of delivery and initiation of breastfeeding within an hour is displayed in Table 19.

Table 19: Relationship between the modes of delivery and initiation of breastfeeding within an hour

\begin{tabular}{|c|c|c|c|c|}
\hline \multirow{2}{*}{ Mode of delivery } & \multicolumn{2}{|c|}{$\begin{array}{c}\text { Initiation of breast feeding in the } \mathbf{1}^{\text {st }} \\
\text { hour of the delivery }\end{array}$} & \multirow{2}{*}{ Total } & \multirow{2}{*}{ P-value } \\
\cline { 2 - 3 } & Yes (\%) & No (\%) & \\
\hline Normal delivery & $140(93.3)$ & $10(6.7)$ & 150 & \\
\hline Cesarean delivery & $42(28.0)$ & $108(72.0)$ & 150 & \multirow{2}{*}{$<0.01$} \\
\hline Total & $182(60.7)$ & $118(39.3)$ & 300 & \\
\hline
\end{tabular}

The above Table 19 depicts the association between the mode of delivery and initiation of breastfeeding within an hour of birth. Among the participants of normal delivery 93.3 percent initiated breastfeeding within an hour of delivery and 72.0 percent participants of cesarean delivery did not initiate breastfeeding within an hour of delivery. There was significant association between the modes of delivery and initiation of breastfeeding within an hour of birth (chi square $=134.2, \mathrm{p}<0.01)$.

\subsection{Relationship between the Modes of Delivery and Skin to Skin Contact between the Mother and Infant After Delivery}

The descriptive information about the association between the mode of delivery and skin to skin contact between the mother and infant after the delivery is displayed in Table 20. The Table 20 depicts the association between the mode of delivery and skin to skin contact between mother and infant after delivery. Among the

Table 20: Relationship between the modes of delivery and skin to skin contact between the mother and infant after delivery

\begin{tabular}{|c|c|c|c|c|}
\hline \multirow{2}{*}{ Mode of delivery } & \multicolumn{2}{|c|}{$\begin{array}{c}\text { Skin to skin contact } \\
\text { between mother and } \\
\text { infant after delivery }\end{array}$} & \multirow{2}{*}{ Total } & \multirow{2}{*}{ P -value } \\
\cline { 2 - 4 } & Yes (\%) & No (\%) & \\
\hline Normal delivery & $145(96.7)$ & $5(3.3)$ & 150 & \multirow{2}{*}{$<0.01$} \\
\cline { 1 - 4 } Cesarean delivery & $28(18.7)$ & $\begin{array}{c}122 \\
(81.2)\end{array}$ & 150 & \\
\hline Total & $\mathbf{1 7 3}$ & $\mathbf{1 2 7}$ & $\mathbf{3 0 0}$ & \\
\hline
\end{tabular}


Aryal et al. Adv. J Social Sci.; Vol. 1 Issue 1, pp: 40-52, November 2017

participants of normal delivery 96.7 percent were able to have skin to skin contact with each other where as in cesarean delivery 81.2 percent participants did not have skin to skin contact with each other.

There was significant association between the modes of delivery and skin to skin contact between the mother and infant after delivery (chi square $=185.9, \mathrm{p}<0.01)$

\section{Discussion}

In working as housewives, most of the participants accepted for having a private place to breastfeed or express the breast milk for their babies. Total $14.7 \%$ and $25.3 \%$ of ND and CS did not have a suitable place for breast feeding or express the milk. The utmost participants of normal delivery stayed in the hospital for 12-24 hours following with 1-3 days. In case of C-section none of them got discharged as soon as ND and stayed for a week and more than a week.

If we compare the initiation of breastfeeding within an hour and the skin to skin contact between mother and baby after birth, almost all of the ND participants had an opportunity to practice both while the participants of CS were not offered any of it. The reason for not practicing were because mother is sick and unable to hold the baby, baby is taken away from mother and there is less or no production of breast milk soon to feed the child. As the mothers of ND were able to feed their babies within 1-3 hours after birth while most of the C-section participants took at least 4-11 hours to feed their breast milk on their own. This might be due to the unfavorable health condition due to the suture. According to the overall participants, the hospital staff were very active in helping to teach the different ways of feeding the baby which is very useful for most of them and few didn't find it useful. In addition, $78 \%$ CS participants fed formula to their babies after they had started breastfeeding while $84.7 \%$ of ND participants did not feeding anything other than breast milk to their babies. This can be the major drawback for the practice of exclusive breastfeeding. Beside on third of the total sample all of the participants developed either of the breast problems such as cracked nipples or abnormal nipples or breast abscess. Despite of the breast problems, determined mothers did not stop breastfeeding their babies. But then again, the few mothers could not bear the pain and did stop feeding breast milk and chose the formula. The practice of expressing the breast milk and measuring the breast milk before feeding the baby is very less among both the deliveries participants. The presumption of the average milk fed by our participants was found to be $45 \mathrm{ml}$ and $30 \mathrm{ml}$ whereas maximum participants denied knowing.

From this study the perspective of the entire participants towards the breastfeeding is found to be on optimistic. They strongly agreed that the benefits of breastfeeding weren't for a limited period and is convenient, healthier, cheaper than formula. They also agreed with the opinion of breast milk being an ideal food for the baby. The maximum numbers of participants were neutral and disagreeing with the statement of not feeding the baby in public places and avoid breastfeeding to prevent any physical changes in mother's body. Similarly, they also agreed with the sentence that formula fed babies are more likely to gain weight more quickly than breastfeed babies and if mother intend to resume work, formula feeding is a better choice for the baby. These could be the drawing factors for the encouragement of formula feeding.

This indicates that the babies who have been fed formula besides breastfeeding cannot be considered as exclusively breastfed. Applying chi square test, it was found that the mode of delivery is significant with both initiation of breastfeeding within an hour $(\mathrm{p}<0.01$, chi square $=134.2)$ and skin to skin contact between mother and infant after delivery $(\mathrm{p}<0.01$, chi square $=185.9)$

From an article of Baby Friendly Hospital Practices: Cesarean Section is a Persistent Barrier to Early Initiation of Breastfeeding [5] confirmed that cesarean section is a significant barrier to the implementation of Baby Friendly Hospital Initiative (BFHI) Step 4 and that hospital practices were amenable to changes that enabled its implementation regardless of the mode of delivery. Similarly, our study also found out that the participants of cesarean section were not practicing the BFHI step 4. In our study, only the two methods; Normal and Cesarean, deliveries were compared by means of the study duration of six months. Applying chi square test, there is a significant association between the mode of delivery and initiation of 
breastfeeding within an hour $(\mathrm{p}<0.01)$. Which means the initiation of breastfeeding within an hour for cesarean delivery is less significant than normal delivery.

As reviewed from the study of Factors Associated with Early Initiation of Breastfeeding among Nepalese Mothers: Further Analysis of Nepal Demographic and Health Survey, 2011 [6] mentioned that two in every three mothers had initiated breastfeeding within one hour of childbirth. The factors associated with the early initiation of breastfeeding were the place of delivery, maternal education and occupation, baby's size at birth and developing regions. Where as in our study the factors associated with the early initiation of breastfeeding is found to the method of delivery. Breastfeeding awareness campaigns or counseling through Nepal's existing strong network of FCHVs, and health workers to pregnant women focusing on less educated, unemployed, and those from the central region may be helpful to improve early initiation of breastfeeding in Nepal. As seen in our study there is proper awareness regarding the benefits of breastfeeding. This study used the data from the Nepal Demographic and Health Survey 2011, which is a nationally representative study.

\section{Conclusion}

As relating the findings with Normal Deliveries and Cesarean Deliveries itself, it has been found that the practice of exclusive breastfeeding is higher among normal deliveries than c- sections. Normal delivery was able to initiate the breastfeeding within an hour and can have skin to skin contact as soon as the delivery. The significance relation $(\mathrm{P}<0.01)$ between both the method of delivery with the initiation of breastfeeding within an hour and skin to skin contact between mother and infant after delivery accepted our alternative hypothesis and rejected the null hypothesis. There are various factors influencing for breastfeeding an infant. The perspective of the entire participants towards the breastfeeding is found to be on optimistic. Exclusive breastfeeding has always been considered as an ideal food for the baby up to six months after birth. The participants of this study also have a positive opinion towards breastfeeding. They agree on the fact of breastfeeding being more convenient, healthier, ideal and cheaper than formula feeding. The maximum participants have also agreed with the statement that formula fed infants are likely to gain weight more quickly than breastfed infants.

\section{Limitation of the study}

Our study has several marked limitations as only small number of patients is studied of the age from 20-30 years, of May and June 2017. To suggest an ideal management, it comes unclear in any field if the sample sizes taken are minimum. Despite of the growing number of the articles in the literature discussing the practice of exclusive breastfeeding after the deliveries, no researches has yet been reached regarding the management of the problems.

\section{Acknowledgement}

It is my great privilege to acknowledge with deep sense of gratitude, the contribution and support given by all the participants from Paropakar Maternity and Women's Hospital, Thapathali. I would also like to show my gratefulness to the Research Team of the respective hospital for the allowance to carry out my research.

\section{How to Cite this Article:}

Aryal, R., \& Sharma, K. (2017, November 25). Comparative Study between the Practices of Exclusive Breastfeeding After Normal Delivery and Cesarean Delivery in Paropakar Maternity and Women's Hospital, Thapathali, Kathmandu Nepal. Advanced Journal of Social Science, 1(1), 40-52. https://doi.org/https://doi.org/10.21467/ajss.1.1.40-52

\section{References}

[1] Subedi, D. (2014). Breastfeeding. Midwifery Nursing Part 3 (pp. 265-310). Jamal, Kathmandu: Medhavi Publication.

[2] Tuitui, R. (2010). Physiology of Lactation. Manual of Midwifery Part 3 (pp. 64-68). Bhotahity, Kathmandu: Vidyarthi Pustak Bhandar.

[3] Adejuyigbe, E. A. (2017). Department of Maternal, Newborn, Child and Adolescent Health. World Health Organization (pp. 1-12). Nigeria: World Health Organization. http://apps.who.int/iris/bitstream/10665/208825/1/9789241549684_eng.pdf 
[4] Tuitui, R. (2010). Problems in Breastfeeding. Manual of Midwifery Part 3 (pp. 95-97). Bhotahity, Kathmandu: Vidyarthi Pustak Bhandar.

[5] Rowe-Murray HJ1, F. J. ( 16 May 2002). Baby Friendly Hospital Practices: Cesarean Section is a Persistent Barrier to Early Initiation of Breastfeeding. https://www.ncbi.nlm.nih.gov/pubmed/12000413

[6] Adhikari, M., Khanal, V., Karkee, R., \& Gavidia, T. (2014). Factors associated with early initiation of breastfeeding among Nepalese mothers: further analysis of Nepal Demographic and Health Survey, 2011. International Breastfeeding Journal, 9(1), 21. https://www.ncbi.nlm.nih.gov/pmc/articles/PMC4260185/

\section{Publish your research article in AIJR journals-}

$\checkmark$ Online Submission and Tracking

$\checkmark$ Peer Reviewed

$\checkmark$ Rapid decision

$\checkmark$ Immediate Publication after acceptance

$\checkmark$ Open Access (Articles freely available online)

$\checkmark$ Retain full copyright of your article.

Submit your article at journals.aijr.in 